See discussions, stats, and author profiles for this publication at: https://www.researchgate.net/publication/329254167

\title{
Profiles of Psychological Flexibility: A Latent Class Analysis of the Acceptance and Commitment Therapy Model
}

Article in Behavior Modification · November 2018

DOI: 10.1177/0145445518820036

\section{CITATIONS}

4

6 authors, including:

Ian Tyndall

University of Chichester

38 PUBLICATIONS 177 CITATIONS

SEE PROFILE

A) Luca Pancani

Università degli Studi di Milano-Bicocca

33 PUBliCATIONS 281 CITATIONS

SEE PROFILE
1,802

Daniel Waldeck

Coventry University

14 PUBLICATIONS 69 CITATIONS

SEE PROFILE

Robert Whelan

Trinity College Dublin

288 PUBLICATIONS 4,518 CITATIONS

SEE PROFILE

Some of the authors of this publication are also working on these related projects:

Project Construct Validity of the AAQ-II View project

Project Neurobehavioral investigation of life-span attention-deficit hyperactivity disorder (ADHD) symptoms View project 
SUGGESTED RUNNING HEAD: PROFILES OF PSYCHOLOGICAL FLEXIBILITY

Title: Profiles of Psychological Flexibility: A latent class analysis of the Acceptance and Commitment Therapy model 


\begin{abstract}
There exists uncertainty for clinicians over how the separate sub-component processes of psychological flexibility, a core construct of the Acceptance and Commitment Therapy model, interact and influence distress experienced. The present study $(N=567)$ employed latent class analysis to (i) identify potential classes (i.e., subgroups) of psychological flexibility based on responses on measures of key sub-component process, and (ii) to examine whether such classes could reliably differentiate levels of self-reported psychological distress and positive and negative emotionality. We found three distinct classes: (i) High Psychological Flexibility, (ii) Moderate Psychological Flexibility, and (iii) Low Psychological Flexibility. Those in the Low Psychology Flexibility class reported highest levels of psychological distress, whereas those in the High Psychological Flexibility class subgroup reported lowest levels of psychological distress. This study provides a clearer view to clinicians of the profile of the broader spectrum of the psychological flexibility model to facilitate change in clients.
\end{abstract}

Keywords: Psychological Flexibility, Acceptance and Commitment Therapy, Experiential Avoidance, Latent Class Analysis 
Psychological flexibility is at the core of the Acceptance and Commitment Therapy (ACT; Hayes, Strosahl, \& Wilson, 1999; 2012) model of behavior change and is defined as the "ability to contact the present moment more fully as a conscious human being, and to change or persist in behavior when doing so serves valued ends" (Hayes, Luoma, Bond, Masuda, \& Lillis, 2006, p. 6). The polar opposite to psychological flexibility is termed psychological inflexibility, characterized by a behavioral pattern of excessive control of a person's thoughts, feelings, and emotions, with a tendency to avoid unpleasant internal experiences at the expense of more effective or valued actions (Levin et al., 2014; but see Kashdan \& Rottenberg, 2010, for a caveat on framing flexibility and inflexibility as opposing ends of a psychological continuum). As put by Renshaw (2018), psychological wellbeing is supported and maintained by psychologically flexible behavior, whereas the development of mental health difficulties is facilitated by psychologically inflexible behavior.

Enhancing a client's psychological flexibility has been a key goal of ACT-based intervention studies (e.g., Berghoff, McDermott, \& Dixon-Gordon, 2018; Fledderus, Bohlmeijer, Fox, Schreurs, \& Spinhoven, 2013; Gloster, Meyer, \& Lieb, 2017; Simon \& Verboon, 2016; Twohig, Plumb-Vilardaga, Levin, \& Hayes, 2015). Moreover, Gloster, Klotsche, Chaker, Hummel, and Huyer (2011) reported that psychological flexibility "adds to the explanation of clinically relevant variables, such as functioning and impairment, beyond well-validated measures of depression, anxiety, and stress as well as anxiety sensitivity and neuroticism” (p. 976). Indeed, Gloster et al. (2017) found that psychological flexibility moderated a wide variety of stressors in a large Swiss sample, and proposed that increasing psychological flexibility could be a desirable and achievable public health target.

Psychological flexibility is a broad, overarching construct comprised of six distinct sub-processes: acceptance, cognitive defusion, self-as-context, present moment awareness, values clarification, and committed action (Hayes et al., 2006). At the other end of the 
spectrum, psychological inflexibility comprises experiential avoidance, cognitive fusion, selfas-content, lack of present moment awareness, lack of values, and lack of commitment to action (Levin et al., 2014). Whereas much research, as noted above, has focused on targeting the overarching construct of psychological flexibility/inflexibility, a growing body of evidence illustrates the utility of individual component sub-processes of psychological inflexibility as potentially useful explanatory concepts in terms of how people cope with psychological distress and suffering in a wide variety of domains (e.g., Bardeen \& Fergus, 2016; Chawla \& Ostafin, 2007; Levin, Hildebrandt, Lillis, \& Hayes, 2012; Monestès et al., 2017; Trindade, Ferreira, \& Pinto-Gouveia, 2017).

Experiential avoidance is the most widely researched component of psychological inflexibility (e.g., Bardeen, Fergus, \& Orcutt, 2013; Gerhart, Baker, Hoerger, \& Ronan, 2014; Karekla \& Panayioutou, 2011; Monestès et al., 2017). It is defined as behavior that attempts to "alter the frequency or form of unwanted private events, including thoughts, memories, and bodily sensations, even when doing so causes personal harm" (Hayes, Pistorello, \& Levin, 2012, p. 981). Experiential avoidance has been linked to a wide range of clinically relevant phenomena (Chawla \& Ostafin, 2007; Hayes, Wilson, Gifford, Follette, \& Strosahl, 1996). For example, experiential avoidance has been found to be a key process in emotional disorders (Spinhoven, Drost, de Rooij, van Hemert, \& Pennix, 2014), depressive symptoms (Kashdan, Breen, Afram, \& Terhar, 2010; Schut \& Boelen, 2017), binge eating (Lillis, Hayes, \& Levin, 2011), body image disturbance (Blakey, Reuman, Bucholz, \& Abramowitz, 2017), social anxiety (Kashdan et al., 2010; Kashdan et al., 2013), chronic pain (Karademas et al., 2017), anxiety sensitivity and stress and anxiety (Bardeen et al., 2013; Bardeen, Fergus, \& Orcutt, 2014), trauma (Lewis \& Naugle, 2017), and post-traumatic stress (Kashdan \& Kane, 2011; Thompson \& Waltz, 2010). Indeed, there have been a number of proposals for the potential of experiential avoidance to serve as a generalized transdiagnostic measure for 
psychopathology (e.g., Lewis \& Naugle, 2017; Monestès et al., 2017; Spinhoven et al., 2014; but see also Levin et al., 2014, for a similar claim for psychological inflexibility more generally).

According to Gillanders et al. (2014), cognitive fusion is conceptualized as a unidimensional construct on a continuum from cognitive fusion to cognitive defusion. A client's level of cognitive fusion is characterized by the extent to which they believe that their negative thoughts are literally true. A particular difficulty is that, apart from the psychological distress that believing (i.e., being fused with) negative and emotionally upsetting thoughts may cause individuals, cognitive fusion often leads to acting in accordance with such problematic thoughts. More explicitly, cognitive fusion is the process in which the content of their thoughts come to exert excessive control over individuals, leads to difficulty in tracking experiences outside of the actual content of those specific thoughts, and feel restricted and compelled to act on what the thoughts say they should do as (McCracken, Barker, \& Chilcott, 2014). To help counteract the process of cognitive fusion, the aim of cognitive defusion, therefore, is to discompose the troublesome functions of negative thoughts by establishing non-literal contexts for the client to observe their thinking as a dynamic ongoing process (Luoma \& Villatte, 2012). This faciltates defusion, or cognitive distancing, rather than only encountering the world as organized through their thoughts. Cognitive fusion and defusion have been found to help account for, amongst other clinical problems, approach-avoidance coping with stress (Donald, Atkins, Parker, Christie, \& Guo, 2017), psychological coping with inflammatory bowel disease (Trindade et al., 2017), suicidal ideation (Roush, Brown, Mitchell, \& Cukrowicz, 2017), depression (Bardeen \& Fergus, 2016), and body image dissatisfaction and eating disorders (Ferreira, Palmeira, \& Trindade, 2014). 
Committed Action is generally conceived as flexible persistence in goal-directed behavior (Hayes et al., 2006; Scott, McCracken, \& Norton, 2016). As a component of ACT, it has most notably been successfully applied in the treatment of chronic pain patients (McCracken \& Morley, 2015). Generally speaking, however, it is a relatively understudied sub-component process of psychological inflexibility. Encouragingly, Trindade, MartaSimoes, Ferreira, and Pinto-Gouveia (2018) examined committed action in both a healthy population and a sample with breast cancer, suggesting promising utility for this subcomponent of psychological flexibility as a therapeutic target. In terms of the present study with the focus on the psychological inflexibility model, it could be more helpfully conceptualized as lack of committed action, or simply inaction.

Contact with the present moment (or more simply, present-moment awareness) is similar to many conceptualizations of mindfulness in the clinical literature (e.g., Brown \& Ryan, 2003; Kabat-Zinn, 2003). It focuses on the assertion that we spend too much of our time thinking about an imagined future we have not yet experienced or ruminating about a past we cannot change. The result of this excessive focus on the constructed future or the past means that we lose connection to our direct and current experience (Luoma \& Villatte, 2012). ACT encourages contact with the present moment via a strong emphasis on an ongoing and flexible awareness of a person's current and direct experiences (i.e., psychological and environmental events), without negative judgments, evaluations, or maladaptive comparisons (Luoma \& Villatte, 2012). With respect to the current study, lack of contact with the present moment reflects a tendency to be stuck in a constructed future or conceptualized past that does not allow for the disruption of unhelpful ruminative cycles as there is no mental space or quietude to allow for more flexible and adaptive response to life's prevailing difficulties or challenges. 
Two further less well-studied sub-components of the psychological inflexibility model are self-as-content and lack of values. For the purposes of the present study, the lack of well-validated and empirically supported measures of self-as-content and values at the time of data collection means that we will not assess those two sub-components of psychological inflexibility.

While acknowledging the burgeoning evidence supporting the validity of some measures assessing individual components of the psychological inflexibility model, Scott, McCracken, and Morley (2016) asserted that there was a clear necessity to examine the interrelationships of component processes in a more focused manner. A few studies have examined the interaction of two or more components of psychological inflexibility (e.g., Bardeen \& Fergus, 2016; Hapenny \& Fergus, 2017; Roush et al., 2017; Tyndall, Waldeck, Riva, Wesselmann, \& Pancani, 2018). Such studies represent an important step in furthering our understanding of how the psychological inflexibility model functions as a theoretical account of psychological distress and lower emotional well-being. In particular, ACT theory suggests that experiential avoidance and cognitive fusion could be conceptualized as a 'pair' that influence emotional regulation (Hayes et al., 2012; see also Francis, Dawson, \& GolijaniMoghaddam, 2016). Bardeen and Fergus (2016), for example, explored the interactive effect of experiential avoidance and cognitive fusion with regard to symptoms of anxiety, depression, and posttraumatic stress. Bardeen and Fergus highlighted a particular risk factor for prolonged psychological distress, and the potential for the development of psychopathology more generally, as the combination of high experiential avoidance and high cognitive fusion.

In the context of psychological distress from perceived ostracism, Tyndall et al. (2018) unpacked Waldeck, Tyndall, Riva, and Chmiel's (2017) finding that psychological inflexibility moderates distress from perceived ostracism with an examination of the 
interaction effect of cognitive fusion and experiential avoidance. Tyndall et al. reported that, rather than the expected interaction effect, a structural equation model analysis found that experiential avoidance alone moderated the psychological distress from perceived ostracism over a period of six months. Such findings indicate that we have much to learn about how the psychological inflexibility model functions as sub-component processes may interact in expected or unexpected ways.

Scott et al. (2016) conducted confirmatory factor analyses on a number of core processes of the ACT model of psychological inflexibility with respect to health and wellbeing related outcome measures in chronic pain patients. More specifically, they administered the original Acceptance and Action Questionnaire (Hayes et al., 2004), the Cognitive Fusion Questionnaire (CFQ; Gillanders et al., 2014), and Committed Action Questionnaire (CAQ-8; McCracken, Chilcott, \& Norton, 2015) along with a measure of 'decentering' which is somewhat related to the ACT model components of cognitive defusion (see Bernstein et al., 2015) and present moment awareness. Scott et al. reported that as there was an observed saturation of items across these measures, in that there was a significant load on one general factor they referred to as 'openness', this suggests that these separate measures do not reliably measure the unique portions of variance relating to purportedly distinct component processes that the model predicts. Moreover, Scott et al. found that there appeared to be two distinct components of decentering and committed action within the overall model. In a somewhat similar vein, Hayes, Villatte, Levin, and Hildebrandt (2011) proposed that within the overarching psychological flexibility model there were three pairs or dyads of the original six components comprising (i) acceptance and defusion (i.e., open), (ii) present-moment awareness and self-as-context (i.e., aware), and (iii) values and committed action (i.e., active). Thus, it is not particularly clear as to whether the psychological 
flexibility/inflexibility model is comprised of six distinct processes, or fewer overlapping processes (e.g., either 2 or 3 processes).

To help address concerns regarding the underlying conceptual structure of the ACT model (e.g., Christodoulou, Michaelides, \& Karekla, 2018; Scott et al., 2016; Vowles, Sowden, \& Ashworth, 2014), the present study proposes that a latent class analysis (LCA; Hagenaars \& McCutcheon, 2002) of core components of the psychological inflexibility model could potentially elucidate the inter-relationships among ACT processes more clearly. Such a powerful analytic technique would potentially provide a clearer view of the psychological inflexibility model than we have seen in the literature to date as it could help isolate and identify significantly different classes of psychological inflexibility. In other words, latent class analysis is a person-centered statistical technique that can help identify subgroups of individuals who share common characteristics (Djelantik, Smid, Kleber, \& Boelen, 2017) according to how they respond on different component measures of the psychological inflexibility model. Furthermore, importantly, the LCA technique can indicate whether these profiles predict levels of self-reported psychological distress or emotional wellbeing.

The present study focused on a latent class analysis of sub-component interrelationships within the broader construct psychological inflexibility by including measures of the following core ACT component processes: (i) experiential avoidance (Brief Experiential Avoidance Questionnaire), (ii) cognitive fusion (Cognitive Fusion Questionnaire), (iii) lack of present moment awareness (5-Facet Mindfulness Questionnaire), and (iv) lack of commitment to action (Committed Action Questionnaire-8); along with (v) the omnibus measure of psychological inflexibility and experiential avoidance (AAQ-II) itself. More specifically, the LCA examined these particular sub-components of the psychological inflexibility model with respect to levels of positive and negative emotionality 
and overall self-reported psychological distress (i.e., depression, anxiety, and stress). Thus, the first aim of the present study was to discover if it was possible to identify significantly different subgroups (i.e., latent classes) of psychologically flexible or inflexible individuals based on a number of core constructs of the ACT model. The second aim was to examine if the different classes of psychological flexibility could meaningfully discriminate levels of self-reported depression, stress, anxiety (i.e., psychological distress), and positivity and negative emotionality. To the best of our knowledge, the present study is the first to explore classes or subgroups of psychological inflexibility. Lastly, while an examination of sociodemographic variables is not typically a concern in research on psychological flexibility, studies using the LCA technique often explore relationships among sociodemographic variables and the latent classes of interest (e.g., Djelantik et al., 2017; Lenferink, de Kejser, Smid, Djelantik, \& Boelen, 2017). Thus, as there was no substantive previous literature to suggest particular effects of sociodemographic variables on psychological flexibility, no specific a priori predictions were made. Notwithstanding, the present study used the LCA technique to examine potential associations between psychological flexibility class membership and sociodemographic variables of gender, relationship status, and education level.

\section{Method}

\section{Participants}

The sample ( $N=557 ; 354$ women, 203 men) were recruited using an online survey distributed through emails to university networks within the UK and websites designed for academic research data collection (e.g., http:///www.findparticipants.com). The participants ranged between 18 and 73 years of age $\left(M_{\text {age }}=27 ; S D=11\right)$. The sample consisted mostly of American (49.2\%) and British (15.4\%) residents. The majority of participants were of white 
racial identity (83\%) and employed in a broad array of industries. More specifically, participants reported that they were employed mostly within the health and social care industry (21\%), education (15\%), computer industry (10\%), office and administration support $(8 \%)$, sales (7\%), government (6\%), and arts and entertainment media (4\%). Before data collection began, the study gained approval by the University of Chichester Research Ethics Committee.

\section{Measures}

Acceptance and Action Questionnaire-II (AAQ-II)

The AAQ-II (Bond et al., 2011) is a 7-item measure of psychological inflexibility. Participants responded to items using a 7-point Likert scale from 1 (not at all true) to 7 (completely true; $\alpha=.93$ ). Sample items include: "My painful memories prevent me from having a fulfilling life" and "I'm afraid of my feelings". Test scores on the AAQ-II have demonstrated good internal consistency and test-retest reliability in community samples (Bond et al., 2011).

\section{Cognitive Fusion Questionnaire (CFQ)}

The CFQ (Gillanders et al., 2014) is a 7-item measure of cognitive fusion that assesses the tendency for people to struggle and become entangled with distressing thoughts. Participants responded to items using a 7-point Likert scale from 1 (not at all true) to 7 (completely true; $\alpha=.87$ ). Sample items include: "I struggle with my thoughts" and "I tend to get very tangled up in my thoughts". The CFQ has demonstrated good internal consistency and construct validity in community samples (Gillanders et al., 2014). 
The BEAQ (Gámez et al., 2014) is a 15-item measure of experiential avoidance, and was developed with separate student, community and patient samples. Participants responded to items using a 6-point Likert scale from 1 (strongly disagree) to 6 (strongly disagree; $\alpha=$ .87 in the present study). The BEAQ has demonstrated good internal consistency and construct validity (Gámez et al., 2014). Sample items include: "The key to a good life is never feeling any pain" and "I would give up a lot not to feel bad".

\section{Committed Action Questionnaire (CAQ-8)}

The CAQ-8 (McCracken et al., 2015) is an 8-item measure of committed action, a component process of psychological flexibility that entails flexible persistence in goaldirected behaviour. Participants responded to items using a 6-point Likert scale from 0 (never true) to 6 (always true; $\alpha=.62$ ). Sample items include: "I prefer to change how I approach a goal rather than quit" and "If I felt distressed or discouraged, I let my commitments slide". Analyses of the CAQ-8 have demonstrated good internal consistency and construct validity (McCracken et al., 2015).

\section{Five Facet Mindfulness Questionnaire (FFMQ-SF)}

The FFMQ-SF (Bohlmeijer, ten Klooster, Fledderus, Veehof, \& Baer, 2011) was developed as a brief version (24 items) of the original 39 item FFMQ (Baer, Smith, Hopkins, Krietemeyer, \& Toney, 2006). The FFMQ-SF assesses five facets of mindfulness including: observing, describing, acting with awareness, non-judging, and non-reactivity. Items were scored on a 5-point Likert-type scale ranging from 1 (never or very rarely true) to 5 (very often or always true). Sample items include: "I find it difficult to stay focused on what's happening in the present moment" and "Usually when I have distressing thoughts or images I can just notice them without reacting”. The FFMQ-SF has demonstrated good internal consistency and construct validity (Bohlmeijer et al., 2011). For the purposes of the present 
study, we used the FFMQ-SF as a unidimensional measure to help ensure stable parameters for the analyses and increase interpretability of the solution. The internal consistency was low to moderate $(\alpha=.60)$.

International-Positive and Negative Affect Schedule Short Form (I-PANAS-SF))

The I-PANAS-SF is a 10-item measure of affectivity, with 5 items assessing positive and 5 items assessing negative affectivity (Thompson, 2007). Items were scored on a 5-point Likert-type scale ranging from 1 (never) to 5 (always). The I-PANAS-SF has demonstrated good internal consistency, temporal stability, construct validity, and cross-cultural factorial invariance (Thompson, 2007). Sample items include a response to the following question: "Thinking about yourself and how you normally feel to what extent do you generally feel?" in terms of a particular term such as "Ashamed" and "Nervous". Internal consistency for positive $(\alpha=.80)$ and negative affectivity $(\alpha=.81)$ was good.

\section{Depression Anxiety and Stress Scales (DASS-21)}

To assess psychological distress, participants completed 21 items from the DASS-21 (Lovibond \& Lovibond, 1995). The DASS-21 has been demonstrated to have sufficient construct validity in non-clinical samples (Henry \& Crawford, 2005). Participants rated the frequency and severity of experiencing psychological distress in the last week. The items were rated on a 4-point Likert scale, where 0 represented "did not apply to me at all" and 3 represented "applied to me very much or most of the time", $(\alpha=.93)$. Sample items include: "I felt down-hearted and blue" and "I felt I was close to panic".

\section{Procedure}

All seven self-report measures were uploaded to the internet with Qualtrics (Qualtrics, 2014) online survey system. Participants were emailed a link to the webpage and responded to standard demographic questions and clicked on a forced-choice Informed Consent 
confirmation question in order to proceed. A randomisation function on Qualtrics was chosen which selected the order of presentation of each of the seven measures at random. Participants completed all seven measures in one logged-in session. There were no missing data as a forced-choice function was activated to ensure each item was responded to before moving on to the next item.

\section{Data Management \& Analysis}

Profiles were identified though a Latent Class Analysis (LCA; for an overview, see Hagenaars \& McCutcheon, 2002). LCA is a technique that tests whether the scores on a set of variables can define homogeneous subgroups of individuals (i.e., classes) that are similar in the levels of these variables, thus identifying different profiles. Typically, several LCA solutions that differ in number of classes extracted are evaluated. The LCA was ran on the composite scores of the AAQ-II, CFQ, BEAQ, CAQ-8, and 5FMQ, in order to identify groups of individuals based on the constructs measured by these instruments.

The best solution (i.e., the best number of classes) was determined from both a statistical and a theoretical standpoint. The following statistical indices were considered: (1) the Bayesian information criteria (BIC), which is a measure of model fit; (2) entropy, which is a measure of certainty of the classification; (3) posterior probability of the classes, which indicates the precision of individual classification. A lower value of the BIC and values of entropy and posterior probabilities close to 1.00 indicate good fit of the solution. In addition, (4) the Lo-Mendell-Rubin adjusted likelihood ratio test (LMR) and, (5) the bootstrapped likelihood ratio test (BLRT) were used to directly compare two solutions, one with $k$ classes and the other one with $k-1$ classes. A non-significant probability value associated to the 2times log-likelihood difference tested by the LMR and BLRT indicates that the narrower 
solution (i.e., $k-1$ classes) does not fit the data significantly worse than the wider one (i.e., $k$ classes), hence it should be preferred.

Statistical indices provide the basis for model selection, but the evaluation of the optimal LCA solution highly depends on theoretical considerations concerning the interpretability and meaningfulness of the profiles, as well as parsimony of the solution and absence of classes with too few members. Once the best LCA solution was determined, psychological and sociodemographic variables were compared among the identified profiles. Specifically, between-subjects ANOVAs were used to detect differences in the levels of depression, anxiety, stress, positive emotions, negative emotions, and age, whereas contingency tables and chi-square test were used to investigate gender (males vs. females), education level (high school or lower vs. higher than high school), and relationship status (singles vs. in a relationship). The LCA was performed using the statistical software Mplus, version 7 (Muthén \& Muthén, 2012), whereas the ANOVAs, contingency tables, and chisquare tests were performed using SPSS, version 24 (IBM Corp., 2016).

\section{Results}

Before conducting LCA, the composite scores of AAQ-II, CFQ, BEAQ, CAQ, and 5FMQ were scaled to facilitate the interpretation of the profiles. Specifically, we converted the scores to a 0-100 range, where 0 indicated the lowest and most maladaptive level of a construct and 100 the highest and most adaptive one. Note that this strategy was employed simply to make the output (i.e., comparing levels of the constructs among classes) more readable in that it allows for greater clarity in viewing which constructs are higher or lower than others. If we had ran the same analysis on the original scales the relationships between the constructs would remain the same, yielding solutions with the same entropy and classes composed of the same participants. 


\section{Identification of Profiles}

Table 1 reports the fit indices of the six LCA models that were run extracting 2, 3, 4, 5, and 6 classes, namely models $\mathrm{K} 2, \mathrm{~K} 3, \mathrm{~K} 4, \mathrm{~K} 5$, and $\mathrm{K} 6$, respectively. The result of the BLRT test was not taken into account in the evaluation of the optimal number of classes because it always supported the wider solution between two competing models, thus it was considered uninformative. No more than six classes were estimated because the nonsignificant probability associated to the LMR that compared $\mathrm{K} 6$ and $\mathrm{K} 5$ models indicated that five classes (i.e., model K5) were sufficient to explain our data and one more class was not really needed. Moreover, the BIC yielded by K6 was higher than that of K5, confirming that five classes were better than six classes and lead to the exclusion of K6 as a possible candidate for the optimal solution. Among the remaining four models, K5 yielded the lowest BIC and the LMR indicated that it performed significantly better than K4. However, two main reasons led to the exclusion of K5 as the optimal solution. First, it showed the lowest entropy and posterior probabilities, revealing a lower certainty and precision of the classification compared to that of the other solutions. Second, the class with the lowest posterior probability accounted for only $6.3 \%$ of the sample, suggesting that this model was not parsimonious. After the exclusion of $\mathrm{K} 5$, the lowest BIC was associated to K4, but, again, its entropy, posterior probabilities, and the LMR test indicated that model K3 performed better than K4. Finally, the comparison between K3 and K2 did not provide clear indications about which of these two models should be preferred from a statistical perspective. Indeed, the LMR test and the BIC supported the three-class solution, whereas entropy and posterior probabilities favored the two-class solution.

Thus, a qualitative evaluation of the profiles that emerged from K3 and $\mathrm{K} 2$ was necessary. $\mathrm{C} 1_{\mathrm{K} 2}$ and $\mathrm{C} 2_{\mathrm{K} 2}$ were qualitatively similar to $\mathrm{C} 1_{\mathrm{K} 3}$ and $\mathrm{C} 3_{\mathrm{K} 3}$, respectively, but they differed in quantitative terms. Indeed, $\mathrm{C} 1_{\mathrm{K} 2}$ and $\mathrm{C} 1_{\mathrm{K} 3}$ drew highly comparable trajectories, 
even though $\mathrm{C} 1_{\mathrm{K} 2}$ variable means were higher than those of $\mathrm{C} 1_{\mathrm{K} 3}$. Similarly, $\mathrm{C} 2_{\mathrm{K} 2}$ and $\mathrm{C} 3_{\mathrm{K} 3}$ were qualitatively comparable, but $\mathrm{C} 22_{\mathrm{K} 2}$ variable means were lower than those of $\mathrm{C} 3_{\mathrm{K} 3}$. By contrast, the trajectory of $\mathrm{C} 2 \mathrm{~K}_{\mathrm{K} 3}$ was in-between those of $\mathrm{C} 1_{\mathrm{K} 3}$ and $\mathrm{C} 3_{\mathrm{K} 3}$ and it was qualitatively different from the trajectories that emerged in the two-class model. A contingency table between the two solutions (i.e., K2 and K3) provided an explanation about what happened moving from the three- to the two-class solution. Indeed, no members of $\mathrm{C} 3 \mathrm{~K} 3$ were also included in $\mathrm{C} 1_{\mathrm{K} 2}$ and no members of $\mathrm{C} 1_{\mathrm{K} 3}$ were also members of $\mathrm{C} 2_{\mathrm{K} 2}$. This is the reason behind the similarities between the two pairs of classes mentioned above (i.e., $\mathrm{C} 1_{\mathrm{K} 2}-$ $\mathrm{C} 1_{\mathrm{K} 3}$ and $\left.\mathrm{C} 2_{\mathrm{K} 2}-\mathrm{C} 3_{\mathrm{K} 3}\right)$.

However, both the K2 classes included a high proportion of cases that were then classified in class $\mathrm{C} 2{ }_{\mathrm{K} 3}$ and that moved close and softened their trajectories compared to those of $\mathrm{C} 1_{\mathrm{K} 3}$ and $\mathrm{C} 3_{\mathrm{K} 3}$. In particular, $\mathrm{C} 1_{\mathrm{K} 2}$ consisted of $53.5 \%$ of $\mathrm{C} 1_{\mathrm{K} 3}$ members and $46.5 \%$ of $\mathrm{C} 2{ }_{\mathrm{K} 3}$ members, whereas $\mathrm{C} 2 \mathrm{~K}_{2}$ consisted of $66.8 \%$ of $\mathrm{C} 3_{\mathrm{K} 3}$ members and $33.2 \%$ of $\mathrm{C} 2 \mathrm{~K}_{3}$ members. In other words, the qualitatively new profile observed in $\mathrm{K} 3$ (i.e., $\mathrm{C} 2{ }_{\mathrm{K} 3}$ ) was split in about two halves that joined $\mathrm{C} 1_{\mathrm{K} 3}$ and $\mathrm{C} 3_{\mathrm{K} 3}$ and formed $\mathrm{C} 1_{\mathrm{K} 2}$ and $\mathrm{C} 22_{\mathrm{K} 2}$ in the two-class solution. Given the uniqueness of $\mathrm{C} 22_{\mathrm{K} 3}$ 's trajectory and the higher discrimination between $\mathrm{C} 1_{\mathrm{K} 3}$ and $\mathrm{C} 3_{\mathrm{K} 3}$ compared to that between their counterparts $\mathrm{C} 1_{\mathrm{K} 2}$ and $\mathrm{C} 2 \mathrm{~K}_{\mathrm{K}}$, the three-class solution (i.e., K3 model) was considered the best model to explain our data (see Figure 1).

\section{Differences among the Profiles of Psychological Flexibility}

Psychological Variables. The between-subjects ANOVA yielded significant results for all the psychological variables, indicating that the profiles differed for the levels of depression, $F(2,554)=214.7, p<.001, \eta^{2}=.44$, anxiety, $F(2,554)=118.9, p<.001, \eta^{2}=$ .30 , stress, $F(2,554)=163.0, p<.001, \eta^{2}=.37$, positive emotions, $F(2,554)=67.3, p<$ $.001, \eta^{2}=.20$, and negative emotions, $F(2,554)=262.4, p<.001, \eta^{2}=.49$. Figure 2 shows means and standard errors of the variables for each profile. A series of Bonferroni post-hoc 
tests was performed to detect differences among profiles. The results revealed that all the pairwise comparisons were significantly different, $p<.001$. Specifically, Class 1 (denoted as Low Psychological Flexibility; 27.5\%) showed the highest level of depression, $M=18.58$, $S D=5.10$, anxiety, $M=15.03, S D=4.52$, stress, $M=18.61, S D=4.41$, negative emotions, $M=20.58, S D=4.29$, and the lowest level of positive emotions, $M=17.84, S D=4.54$; Class 3 (denoted as High Psychological Flexibility; 32.5\%) showed the lowest level of depression, $M=9.26, S D=2.76$, anxiety, $M=8.93, S D=2.21$, stress, $M=10.81, S D=3.08$, and negative emotions, $M=11.24, S D=2.68$, and the highest level of positive emotions, $M=$ 23.62, $S D=4.27$; finally, Class 2 (Moderate Psychological Flexibility; 40\%) showed intermediate levels of depression, $M=13.04, S D=4.25$, anxiety, $M=11.43, S D=3.81$, stress, $M=14.14, S D=4.21$, negative emotions, $M=14.87, S D=4.03$, and positive emotions, $M=20.63, S D=4.77$.

Sociodemographic Variables. The between-subjects ANOVA on age was significant, $F(2,554)=19.52, p<.001, \eta^{2}=.07$. A Bonferroni post-hoc test revealed that Class 3 (High Psychological Flexibility), $M=31.88, S D=13.88$, significantly differed from Class 1 (Low Psychological Flexibility), $M=25.39, S D=7.91$, and Class 2 (Moderate Psychological Flexibility), $M=26.20, S D=9.37, p<.001$, but no difference was detected between the two latter profiles. Concerning the other sociodemographic variables, the Appendix reports contingency tables between these variables and the profiles. Gender, $\chi^{2}(2)=$ $6.39, p=.041$, and relationship status, $\chi^{2}(2)=8.53, p=.014$, were significantly associated with the profiles, whereas education level was not $\chi^{2}(2)=1.14, p=.56$. Adjusted standardized residuals (ASRs) were then computed for each cell of the tables and examined to detect deviations from a random distribution of cases. Indeed, an ASR higher than 2.0 (or lower than -2.0) indicates that cases in that cell are overrepresented (or underrepresented) compared to what would be expected by chance. Concerning gender, males were 
underrepresented (and females overrepresented) in Class 1 (Low Psychological Flexibility). Concerning relationship, singles were overrepresented in Class 1 (Low Psychological Flexibility) and underrepresented in Class 3 (High Psychological Flexibility), whereas the opposite was observed for participants in a relationship.

\section{Discussion}

In the present study, we aimed to identify distinct subgroups among psychologically flexible or inflexible individuals based on profiles of key constructs of the ACT model. Moreover, a further aim was to explore whether such potential classes could discriminate self-reported symptoms of psychological distress (i.e., depression, anxiety, and stress) and levels of positive and negative emotionality. Three subgroups were identified: (a) a High Psychological Flexibility subgroup characterized by low levels of experiential avoidance and cognitive fusion, and high levels of present-moment awareness and committed action. Moreover, the High Psychological Flexibility subgroup reported low levels of depression, anxiety, stress, and negative emotions while endorsing a high level of positive emotions; (b) a Moderate Psychological Flexibility subgroup characterized medium to moderate levels of experiential avoidance, cognitive fusion, present-moment awareness, committed action. Conjointly, the Moderate Psychological Flexibility subgroup reported moderate levels of depression, stress, anxiety, and positive and negative emotions; (c) a Low Psychological Flexibility subgroup characterized by high levels of experiential avoidance and cognitive fusion and low levels of mindful awareness and committed action. Furthermore, the Low Psychological Flexibility subgroup endorsed high levels of depression, stress, and anxiety, along with high levels of negative emotions and low levels of positive emotions. Thus, our results highlight that subgroups of psychologically flexible or inflexible individuals can be 
clearly distinguished based on core components of the ACT model. Furthermore, each of the three classes of psychological flexibility identified here reported significantly different levels of psychological distress and positive and negative emotionality.

The present study provides support for the utility of the broad spectrum of the ACT model of psychological flexibility, rather than overreliance on single measures of psychological flexibility or inflexibility. Moreover, the current data are noteworthy clinically in that the High Psychological Flexibility class all reported DASS-21 (i.e., depression, anxiety, and stress) scores lower than 12 while the Low Psychological Flexibility class reported distress scores of 15 or over on all three DASS components. The fact that the that LCA identified a Low Psychological Flexibility group in a non-clinical sample to report scores in what is considered within a moderately distressed range highlights the potential clinical utility of the overarching construct of psychological flexibility/inflexibility (see also Gloster et al., 2017; Levin et al., 2014). It is worth noting at this point, that as is typically the case with LCA, that the labels assigned (i.e., High, Moderate, and Low Psychological Flexibility) are descriptive and cautious in their designation and scope. It is possible, of course, to generate and assign other more eye-catching labels. However, we feel that these terms best describe the three distinct classes without extrapolating beyond the data that emerged in our analyses based on what is generally reported in the empirical literature using these scales employed.

It was interesting to observe (see Figure 1) across the three separate profiles of psychological flexibility that three particular sub-component processes - experiential avoidance, committed action, and mindfulness/contact with the present moment - were remarkably stable in that if you knew a person's score on experiential avoidance you could quite readily predict their score on committed action and contact with the present moment with reasonable accuracy. Likewise, if you knew a person's level of committed action, you 
could quite feasibly predict their probable level of experiential avoidance and contact with the present moment. This might suggest that experiential avoidance, committed action, and present-moment awareness together form a particular cluster within psychological flexibility that likely share an underlying latent factor. Furthermore, psychological inflexibility as assessed by the AAQ-II and cognitive fusion appeared to form a separate cluster within the overall model. This is somewhat unsurprising as the items of both the AAQ-II and CFQ have been found to load onto the same factor in certain samples (Gillanders et al. 2014; Scott et al., 2016).

There are various competing iterations of the underlying conceptual model of psychological flexibility/inflexibility in the literature (Christodoulou et al., 2018). In general terms, they are purported as (i) the six interrelating components structure outlined above with the overarching construct of psychological inflexibility (Hayes et al., 2006), (ii) a three-factor structure (i.e., Hayes et al.'s., 2011, conceptualization of three pairs or dyads of the original six components comprising acceptance and defusion, present-moment awareness and self-ascontext, and values and committed action; see also Frances et al., 2016; Vowles et al., 2014), and (iii) a two-factor solution consisting of mindfulness and acceptance, and commitment and behavior change (e.g., as noted earlier Scott et al., 2016, proposed a general underlying openness factor along with two distinct components of decentering and committed action; see also Villatte et al.'s, 2016, ACT OPEN and ACT ENGAGED modules). As the present study did not include measures of all six components of the psychological inflexibility model it is not possible to fully endorse any of the three competing conceptual models. However, as noted above, what we can gauge from this latent class analysis approach is that presentmoment awareness (i.e., mindfulness) and acceptance (i.e., opposite of experiential avoidance as measured by the BEAQ) and committed action appear to form a quite stable latent cluster. This does not fit readily with Scott et al.'s distinction between decentering and committed 
action as separate factors within the model. As acknowledged earlier, as we did not measure self-as-content/self-as-context or values it is difficult to elucidate which conceptual model appears to have superior explanatory power. Nonetheless, the present data (see Figure 1) seem to suggest that the component processes have a complex interrelationship that suggests there might be more support for a three- or two-factor structure. Moreover, it seems from the present study that considering experiential avoidance and cognitive fusion as a pair or dyad (e.g., Hayes et al., 2011) within the overall model might not be useful as they appear functionally distinct, at least according to the somewhat limited self-report measures of these constructs (i.e., BEAQ and CFQ).

Furthermore, it was not possible within the design of the present study (i.e., single time-point cross-sectional method) to examine any cause and effect relationship between individual sub-components of the model and overarching construct of psychological inflexibility. As noted by Kashdan and Rottenberg (2010), amongst others, it is difficult to assess whether psychological inflexibility causes experiential avoidance, cognitive fusion, inaction, and so on, or whether these components cause a person to be psychologically inflexible in their behavior. This causal directionality problem remains a significant concern for theorists working with the psychological inflexibility model (Christodoulou et al., 2018). One approach that future researchers could consider employing is latent growth curve analysis with data collection at multiple time points.

There could be a case for arguing that the ACT model of psychological flexibility/inflexibility does not espouse such psychometric measures of sub-component processes of the model as 'trait-like' constructs. Thus, it could be debated that a latent class analysis might not actually fit with how ACT processes are conceptualized or operationalized. For example, in some ACT writings the six component processes are referred to as skills that can be altered or modified, rather than traits that are somewhat fixed 
(see Christodoulou et al., 2018). However, it is apparent in some recent psychometric measure developments that, for example, the measure of cognitive fusion employed here (the CFQ) was designed as a trait measure because Bolderston et al. (2018) have developed and validated a separate State Cognitive Fusion Questionnaire (SCFQ). Therefore, it is clear that at least in the manner that the measures employed in the present study were designed as instruments to assess trait-like constructs and indeed are typically utilized by researchers in the empirical literature as such, that there is ample justification for examining the psychological flexibility model with latent class approaches.

There exists some degree of uncertainty and confusion over the construct and discriminant validity of some key ACT process measures (e.g., Rochefort, Baldwin, \& Chmielewski, 2018; Scott et al., 2016; Vaughan-Johnson, Quickert, \& MacDonald, 2017; Wolgast, 2014), and debate over how to assess the broad overarching construct of psychological inflexibility more generally (e.g., Fergus et al., 2012; Francis et al., 2016; Renshaw, 2018). The present study provides further support for the position that the AAQ-II and the BEAQ assess experiential avoidance in different ways or might not measure the same construct (e.g., Gàmez et al., 2014; Rochefort et al., 2018, Tyndall, Waldeck, Pancani, et al., 2018). The BEAQ scores were quite stable with respect to committed action and contact with the present moment across all three subgroups of psychological flexibility whereas the AAQII scores were the most volatile or unstable. For example, at low levels of psychological flexibility the AAQ-II scores were lower than BEAQ scores, while at high levels of psychological flexibility the AAQ-II scores were higher than BEAQ scores. Scores on both measures were quite similar at moderate levels of psychological flexibility though. It could be argued that the AAQ-II scores being so different from BEAQ scores at low and high levels of psychological flexibility indicates that it is a more useful measure of experiential avoidance as it might more reliably represent the level of a person's psychological distress or wellbeing 
than the BEAQ. However, it could also be argued that the AAQ-II scores at low and high levels of psychological flexibility support Wolgast's (2014) proposition that the AAQ-II is actually a measure of psychological distress (see also Rochefort et al., 2018's claim that it reflects the personality trait of neuroticism) rather than experiential avoidance. A cautious interpretation from the present study is that, as the BEAQ scores fit more readily with levels of committed action and contact with the present moment, the BEAQ is the more effective or favorable measure of experiential avoidance taking the overall ACT model into account. It should be acknowledged that it might take some time for this message to permeate the field as the use of the AAQ-II to assess experiential avoidance remains deeply ingrained in the clinical and non-clinical literatures (e.g., Blakey et al., 2017; Karademas et al., 2017; Karekla \& Panayioutou, 2011; Monestès et al., 2017).

While no specific a priori predictions were made regarding sociodemographic variables and psychological flexibility as there was little extant empirical literature to suggest expected differences, it was intriguing to note the higher levels of psychological flexibility among those in relationships than single persons. This interesting finding needs to be further explored in future research. Females were more likely than males to be characterized by low levels of psychological flexibility. Indeed, previous research has demonstrated that females tend to experience higher levels of psychological distress and utilize avoidant coping strategies compared to males (Matud, 2004). Furthermore, the education level achieved by an individual had no relationship to their profile of psychological flexibility. Future researchers could explore these observed gender and relationship differences in greater depth and in different contexts (e.g., specific psychological disorders) to see whether they represent a stable finding or one unique to the present study sample.

A limitation of the present study is that it relied exclusively on self-report questionnaire measures at one time point. Thus, it is possible that shared variance effects 
could have inflated associations between variables. A second potential limitation could be that we employed a measure of mindfulness best represented by a five-factor solution as a single measure. We acknowledge that this is not ideal and future researchers could be encouraged to employ a different measure such as the Mindfulness Attention Awareness Scale (MAAS; Brown \& Ryan, 2003) instead. A further limitation of the current study is that it did not assess self-as-content or values due to a lack of sufficient empirical support (but see Moran, Almada, \& McHugh, 2018) for measures of these sub-component processes for our purposes. However, it should be acknowledged that a number of instruments have been developed and researchers could consider including measures such as the Valuing Questionnaire (Smout, Davies, Burns, \& Christie, 2014) and the Self Experiences Questionnaire (Yu, McCracken, \& Norton, 2016) in future LCA analyses of the psychological inflexibility model. Similarly, future research could consider alternative measures of the overarching construct of psychological flexibility such as the Comprehensive Assessment of Acceptance and Commitment Therapy (CompACT; Frances et al., 2016), the Avoidance and Fusion Questionnaire (Greco, Baer, \& Lambert., 2008), or the Multidimensional Psychological Flexibility Inventory (MPFI; Rolffs, Rogge, \& Wilson, 2018), rather than the AAQ-II administered here. Researchers should be mindful, however, of the fact that it is not well known, as of yet, whether adding more indicators to a latent class analysis is a positive or negative analytic strategy (Wurpts \& Geiser, 2014).

Future research could consider applying a latent class analysis to samples in a variety of clinical domains such as social anxiety disorder, clinical depression, obsessive-compulsive disorder, eating disorders, and post-traumatic stress disorder. Indeed, a latent class analysis with particular clinical sub-populations could potentially aid in the development of tailored therapeutic interventions for specific groups. For example, it might emerge that different 
psychological disorders or conditions are typically characterized by rather distinctive clusters or profiles.

In conclusion, the current study represents an important addition to the literature as the first study to identify distinct subgroups of psychological flexibility based on core constructs of the ACT model using a latent class analysis. From a clinical perspective, this discovery was important as each of the three subgroups or classes of psychological flexibility reported significantly different levels of psychological distress and emotionality. This could aid clinicians and researchers to more accurately represent a client's level of psychological flexibility across the broader spectrum of the ACT model, rather than the heretofore more typically reported reliance on one measure of psychological flexibility alone. Furthermore, such analyses as these could help provide clinicians with a more nuanced picture of mediation effects in ACT-based intervention studies to give a clearer picture as to which specific sub-components of psychological flexibility drive the improvements often observed. We hope that the current study serves to stimulate much needed research on sub-component processes within the ACT model of psychological flexibility.

Disclosure of Interest: No author has a conflict of interest to declare. 


\section{References}

Baer, R. A., Smith, G. T., Hopkins, J., Krietemeyer, J., \& Toney, L. (2006). Using self-report assessment methods to explore facets of mindfulness. Assessment, 13, 27-45. Doi:10.177/107319105283504

Bardeen, J. R., \& Fergus, T. A. (2016). The interactive effect of cognitive fusion and experiential avoidance on anxiety, depression, stress and posttraumatic stress symptoms. Journal of Contextual Behavioral Science, 5, 1-6. doi:10.1016/j.jcbs.2016.02.002

Bardeen, J. R., Fergus, T. A., \& Orcutt, H. K. (2013). Experiential avoidance as a moderator of the relationship between anxiety sensitivity and perceived stress. Behavior Therapy, 44, 459-469.

Bardeen, J. R., Fergus, T. A., \& Orcutt, H. K. (2014). The moderating role of experiential avoidance in the prospective relationship between anxiety sensitivity and anxiety. Cognitive Therapy and Research, 38, 465-471.

Berghoff, C. R., McDermott, M. J., \& Dixon-Gordon, K. I. (2018). Psychological flexibility moderates the relation between PTSD symptoms and daily pain interference. Personality and Individual Differences, 124, 130-134. Doi:10.1016/j.paid.2017.12.012

Bernstein, A., Hadash, Y., Lichtash, Y., Tanay, G., Shepherd, K., \& Fresco, D. M. (2015). Decentering and related constructs: A critical review and metacognitive processes model. Perspectives on Psychological Science, 10, 599-617. doi: $10.1177 / 1745691615594577$.

Blakey, S. M., Reuman, L., Bucholz, J. L., \& Abramowitz, J. S. (2017). Experiential avoidance and dysfunctional beliefs in the prediction of body image disturbance in a 
non-clinical sample of women. Body Image, 22, 72-77. doi:

10.1016/j.bodyim.2017.06.003

Bohlmeijer, E., ten Klooster, P. M., Fledderus, M., Veehof, M., \& Baer, R. (2011).

Psychometric properties of the five facet mindfulness questionnaire in depressed adults and development of a short form. Assessment, 18, 308-320. doi: $10.1177 / 1073191111408231$

Bolderston, H., Gillanders, D. T., Turner, G., Taylor, H. C., Ni Mhaoileoin, D., \& Coleman, A. (2018). The initial validation of a state version of the Cognitive Fusion Questionnaire. Journal of Contextual Behavioral Science.

Doi:10.1016/j.jcbs.2018.04.002

Bond, F. W., Hayes, S. C., Baer, R. A., Carpenter, K. M., Guenole, N., Orcutt, H. K., ...\& Zettle, R. D. (2011). Preliminary psychometric properties of the Acceptance and Action Questionnaire-II: A revised measure of psychological flexibility and experiential avoidance. Behavior Therapy, 42, 676-688. doi: 10.1016/j.beth.2011.03.007

Brown, K. W., \& Ryan, R. M. (2003). The benefits of being present: Mindfulness and its role in psychological well-being. Journal of Personality and Social Psychology, 84, 822848. doi:10.1037/0022-3514.84.4.822

Chawla, N., \& Ostafin, B. (2007). Experiential avoidance as a functional dimensional approach to psychopathology: An empirical review. Journal of Clinical Psychology, 63, 871-890. Doi:10.1002/jclp.20400

Christodoulou, A., Michaelides, M., \& Karekla, M. (2018). Network analysis: A new psychometric approach to examine the underlying ACT model components. Journal of Contextual Behavioral Science. Doi:10.1016/j.jcbs.2018.10.002 
Djelantik, A. A. A. M. J., Smid, G. E., Kleber, R. J., \& Boelen, P. A. (2017). Symptoms of prolonged grief, post-traumatic stress, and depression after loss in a Dutch community sample: A latent class analysis. Psychiatry Research, 247, 276-281. doi: 10.1016/j.psychres.2016.11.023

Donald, J. N., Atkins, P. W. B., Parker, P. D., Christie, A. M., \& Guo, J. (2017). Cognitive defusion predicts more approach and less avoidance coping with stress, independent of threat and self-efficacy appraisals. Journal of Personality, 85, 716-729. doi: 10.1111/jopy. 12279

Fergus, T. A., Valentiner, D. P., Gillen, M. J., Twohig, M. P., Abromowitz, J. S., \& McGrath, P. B. (2012). Assessing psychological inflexibility: The psychometric properties of the avoidance and fusion questionnaire for youth in two adult samples. Psychological Assessment, 24, 402-408. doi: 10.1037/a0025776

Ferreira, C., Palmeira, L., \& Trindade, I. A. (2014). Turning eating psychopathology risk factors into action. The pervasive effect of body imaged-related cognitive fusion. Appetite, 80, 137-142.

Fledderus, M., Bohlmeijer, E. T., Fox, J. P., Schreurs, K. M., \& Spinhoven, P. (2013). The role of psychological flexibility in a self-help acceptance and commitment therapy intervention for psychological distress in a randomized control trial. Behavior Research and Therapy, 51, 142-151. doi: 10.1016/j.brat.2012.11.007

Francis, A. W., Dawson, D. L., \& Golijani-Moghaddam, N. G. (2016). The development and validation of the comprehensive assessment of Acceptance and Commitment Therapy processes (CompACT). Journal of Contextual Behavioral Science, 5, 134-145. doi.org/10.1016/j.jcbs.2016.05.003 
Gámez, W., Chmielewski, M., Kotov, R., Ruggero, C., Suzuki, N., \& Watson, D. (2014). The Brief Experiential Avoidance Questionnaire: Development and initial validation. Psychological Assessment, 26, 35-45. doi: 10.1037/a0034473

Gerhart, J. I., Baker, C. N., Hoerger, M., \& Ronan, G. F. (2014). Experiential avoidance and interpersonal problems: A moderated mediation model. Journal of Contextual Behavioral Science, 3, 291-298.

Gillanders, D. T., Bolderston, H., Bond, F. W., Dempster, M., Flaxman, P. E., Campbell, L., ...\& Remington, B. (2014). The development and initial validation of the Cognitive Fusion Questionnaire. Behavior Therapy, 45, 83-101. doi: 10.1016/j.beth.2013.09.001

Gloster, A. T., Klotsche, J., Chaker, S., Hummel, K. V., \& Hoyer, J. (2011). Assessing psychological flexibility: What does it add above and beyond existing constructs? Psychological Assessment, 23, 970-982. doi: 10.1037/a0024135

Gloster, A. T., Meyer, A. H., \& Lieb, R. (2017). Psychological flexibility as a malleable public health target: Evidence from a representative sample. Journal of Contextual Behavioral Science, 6, 166-171. doi:10.1016/j.jcbs.2017.02.003

Greco, L. A., Baer, R. A., \& Lambert, W. (2008). Psychological inflexibility in childhood and adolescence: Development and evaluation of the Avoidance and Fusion Questionnaire for Youth. Psychological Assessment, 24, 402-408. doi: 10.1037/10403590.20 .2 .93

Hagenaas, J. A., \& McCutcheon, A. L. (2002). Applied latent class analysis. Cambridge, UK: Cambridge University Press.

Hapenny, J. E., \& Fergus, T. A. (2017). Cognitive fusion, experiential avoidance, and their interactive effect: Examining associations with thwarted belongingness and perceived 
burdensomeness. Journal of Contextual Behavioral Science, 6, 35-41. doi:10.1016/j.jcbs.2016.10.004

Hayes, S. C., Luoma, J. B., Bond, F. W., Masuda, A., \& Lillis, J. (2006). Acceptance and commitment therapy: Model, processes, and outcomes. Behavior Research and Therapy, 44, 1-25. doi.org/10.1016/j.brat.2005.06.006

Hayes, S. C., Pistorello, J., \& Levin, M. E. (2012). Acceptance and commitment therapy as a unified model of behavior change. The Counselling Psychologist, 40, 976-1002. doi.org/10.1177/0011000012460836

Hayes, S. C., Strosahl, K. D., \& Wilson, K. G. (1999). Acceptance and commitment therapy: An experiential approach to behavior change. New York, NY: Guilford Press.

Hayes, S. C., Strosahl, K. D., \& Wilson, K. G. (2012). Acceptance and commitment therapy: The process and practice of mindful change, $\left(2^{\text {nd }} e d\right)$. New York, NY: Guilford Press.

Hayes, S. C., Strosahl, K. D., Wilson, K. G., Bissett, R. T., Pistorello, J., Toarmino, D., ...McCurry, S. (2004). Measuring experiential avoidance: A preliminary test of a working model. The Psychological Record, 54, 553-578.

Hayes, S. C., Villatte, M., Levin, M., \& Hildebrandt, M. (2011). Open, aware, and active: Contextual approaches as an emerging trend in the behavioral and cognitive therapies. Annual Review of Clinical Pychology, 7, 141-168. doi: 10.1146/annurev-clinpsy-032210104449

Hayes, S. C., Wilson, K. G., Gifford. E. V., Follette, V. M., \& Strosahl, K. (1996). Experiential avoidance and behavioral disorders: A functional diagnostoc approach to diagnosis and treatment. Journal of Consultimg and Clinical Psychology, 64, 11521168. doi.org/10.1037/0022-006X.64.6.1152 
Henry, J. D., \& Crawford, J. R. (2005). The short-form of the Depression Anxiety Stress Scales (DASS-21): Construct validity and normative data in a large non-clinical sample. British Journal of Clinical Psychology, 44, 227-239.

Doi:10.1348/014466505X29567

IBM Corp. (2016). Statistical Package for Social Sciences. Armonk, NY: IBM Corp.

Kabat-Zinn, J. (2003). Mindfulness-based interventions in context: Past, present and future. Clinical Psychology: Science and Practice, 10, 144-156.

Karademas, E. C., Karekla, M., Flourini, M., Vasilou, V. S., Kasinopoulos, \& Papacosta, S. S. (2017). The impact of experiential avoidance on the relationship between illness representations, pain catastrophising, and pain interference in chronic pain. Psychology \& Health, 32, 1461-1484. doi. 10.1080/08870446.2017.1346193.

Karekla, M., \& Panayiotou, G. (2011). Coping and experiential avoidance: Unique or overlapping constructs? Journal of Behavior Therapy and Experimental Psychiatry, 42, 163-170. doi: 10.1016/j.jbtep.2010.10.002

Kashdan, T. B., Breen, W. E. Afram, A., Terhar, D. (2010). Experiential avoidance in idiographic, autobiographical memories: Construct validity and links to social anxiety, depressive, and anger symptims. Journal of Anxiety Disorders, 24, 528-534.

Kashdan, T. B., Farmer, A. S., Adams, L. M., Ferssizidis, X., McKnight, P. E., \& Nezlek, J. B. (2013). Distinguishing healthy adults from people with social anxiety disorder: Evidence for the value of experiential avoidance and positive emotions in everday social interactions. Journal of Abnormal Social Psychology, 122, 645-655. 
Kashdan, T. B., \& Kane, J. Q. (2011). Post-traumatic distress and the presence of posttraumatic growth and meaning in life: Experiential avoidance as a moderator. Personality and Individual Differences, 50, 84-89. Doi:10.1016/j.paid.201.08.028

Kashdan, T. B., \& Rottenberg, J. (2010). Psychological flexibility as a fundamental aspect of health. Clinical Psychology Review, 30, 865-878. doi.org/10.1016/j.cpr.2010.03.001

Lenferink, L. I. M., de Kejser, J., Smid, G. E., Djelantik, A. A. A. M. J., \& Boelen, P. A. (2017). Prolonged grief, depression, and posttraumatic stress disorder in disasterbereaved individuals: Latent class analysis. European Journal of Psychotraumatology, 8, 1298311. Doi:10.1080/20008198.2017.1298311

Levin, M. E., Hildebrandt, M. J., Lillis, J., \& Hayes, S. C. (2012). The impact of treatment components suggested by the psychological flexibility model: A meta-analysis of laboratory-based component studies. Behavior Therapy, 43, 741-756. doi: 10.1016/j.beth.2012.05.003

Levin, M. E., MacLane, C., Daflos, S., Pistorello, J., Hayes, S. C., Seeley, J., \& Biglan, A. (2014). Examining psychological inflexibility as a trandiagnostic process across psychological disorders. Journal of Contextual Behavioral Science, 3, 155-163. doi:10.1016/j.jcbs.2014.06.003

Lewis, M., \& Naugle, A. (2017). Measuring experiential avoidance: Evidence toward mutlidimensional predictors of trauma sequelae. Behavioral Sciences, 7, 9. Doi.org/10.3390/bs7010009

Lillis, J., Hayes, S. C., \& Levin, M. E. (2011). Binge eating and weight control: The role of experiential avoidance. Behavior Modification, 35, 252-264. 
Lovibond, P. F., \& Lovibond, S. H. (1995). The structure of negative emotional states: Comparison of the Depression Anxiety Scales (DASS) with the Beck Depression and Anxiety Inventories. Behavior Research and Therapy, 33, 335-343. doi.org/10.1016/0005-7967(94)00075-U

Luoma, J. B., \& Villatte, J. L. (2012). Mindfulness in the treatment of suicidal individuals. Cognitive and Behavioral Practice, 19, 265-276.

Matud, M. P. (2004). Gender differences in stress and coping styles. Personality and Individual Differences, 37, 1401-1415. doi: 10.1016/j.paid.2004.01.010

McCracken, L. M., Barker, E., \& Chilcot, J. (2014). Decentering, rumination, cognitive defusion, and psychological flexibility in people with chronic pain. Journal of Behavioral Medicine, 37, 1215-1225.

McCracken, L., Chilcot, J., \& Norton, S. (2015). Further development in the assessment of psychological flexibility: A shortened Committed Action Questionnaire (CAQ-8). Euopean Journal of Pain, 19, 677-685. doi: 10.1002/ejp.589

McCracken, L. M., \& Morley, S. (2015). The psychological flexibility model: A basis for integration and progress in psychological approaches to chronic pain management. The Journal of Pain, 15, 221-234. doi: 10.1016/j.jpain.2013.10.014

Monestès, J. L., Karekla, M., Jacobs, N., Michaelides, M., Hooper, N., Kleech, M., Ruiz, F., Miselli, G., Presti, G., Luciano, C., Villatte, M., Bond, F., Kishita, N., \& Hayes, S. C. (2017). Experiential avoidance as a common psychological process in European cultures. European Journal of Psychological Assessment. Doi.org/10.1027/1015$5759 / \mathrm{a} 00327$ 
Moran, O., Almada, P., \& McHugh, L. (2018). An investigation into the relationship between the three selves (self-as-context, self-as-process and self-as-context) and mental health in adolescents. Journal of Contextual Behavioral Science, 7, 55-62. doi.org/10.1016/j.jcbs.2018.01.002

Renshaw, T. L. (2018). Probing the relative psychometric validity of three measures of psychological inflexibility. Journal of Contextual Behavioral Science, 7, 47-54. Doi:10.1016/j.jcbs.2017.12.001

Rochefort, C., Baldwin, A., \& Chmielewski, M. (2018). Experiential avoidance: An examination of the construct validity of the AAQ-II and MEAQ. Behavior Therapy, 49, 435-449. doi.org/10.1016/j.beth.2017.08.008

Rolffs, J. L., Rogge, R. D., \& Wilson, K. G. (2018). Disentangling components of flexibility via the hexaflex model: Development and validation of the Multidimensional Psychological Flexibility Inventory (MPFI). Assessment, 25, 458-482.

Roush, J. F., Brown, S. L., Mitchell, S. M., \& Cukrowicz, K. C. (2017). Experiential avoidance, cognitive fusion, and suicide ideation among psychiatric inpatients: The role of interpersonal needs. Psychotherapy Research, ePub, doi. 10.1080/10503307.2017.1395923.

Scott, W., McCracken, L. M., \& Norton, S. (2016). A confirmatory factor analysis of facets of psychological flexibility in a sample of people seeking treatment for chronic pain. Annals of Behavioral Medicine, 50, 285-296. Doi: 10.1007/s12160-015-9752-x

Simon, E., \& Verboon, P. (2016). Psychological inflexibility and child anxiety. Journal of Child and Family Studies, 25, 3565-3573. Doi: 10.1007/s10826-016-0522-6 
Smout, M., Davies, M., Burns, N., \& Christie, A. (2014). Development of the Valuing Questionnaire (VQ). Journal of Contextual Behavioral Science, 3, 164-172. doi:10.1016/j.jcbs.2014.06.001

Spinhoven, P., Drost, J., de Rooij, M., van Hemert, A. M., \& Pennix, B. W. (2014). A longitudinal study of experiential avoidance in emotional disorders. Behavior Therapy, 45, 840-850. doi: 10.1016/j.beth.2014.07.001

Thompson, B. L. \& Waltz, J. (2010). Mindfulness and experiential avoidance as predictors of posttraumatic stress disorder avoidance symptom severity. Journal of Anxiety Disorders, 24, 409-415.

Thompson, E. R. (2007). Development and validation of an internationally reliable shortform of the Positive and Negative Affect Schedule (PANAS). Journal of CrossCultural Psychology, 38, 227-242. doi.org/10.1177/0022022106297301

Trindade, I., A., Ferreira, C., \& Pinto-Gouveia, J. (2018). The longitudinal effects of emotion regulation on physical and psychological health: A latent growth analysis exploring the role of cognitive fusion in inflammatory bowel disease. British Journal of Health Psychology, 23, 171-185. doi: 10.1111/bjhp.12280

Trindade, I. A., Marta-Simoes, J., Ferreira, C., \& Pinto-Gouveia, J. (2018). Developments on committed action: Validity of the CAQ- 8 and analysis of committed action's role in depressive symptomatology in breast cancer patients and healthy individuals. Clinical Psychology and Psychotherapy, 25, e42-e50. Doi:10.1007/s10880-017-9536-5.

Twohig, M. P., Plumb-Vilardaga, J. C., Levin, M. E., \& Hayes, S. C. (2015). Changes in psychological flexibility during acceptance and commitment therapy for obsessive compulsive disorder. Journal of Contextual Behavioral Science, 4, 196-202. doi: 10.1016/j.beth.2009.08.002 
Tyndall, I., Waldeck, D., Pancani, L., Whelan, R., Roche, B., \& Dawson, D. L. (2018). The Acceptance and Acton Questionnaire-II (AAQ-II) as a measure of experiential avoidance: Concerns over discriminant validity. Journal of Contextual Behavioral Science. Doi:10.1016/j.jcbs.2018.09.005

Tyndall, I., Waldeck, D., Riva, P., Wesselmann, E. D., \& Pancani, L. (2018). Psychological flexibility and ostracism: Experiential avoidance rather than cognitive fusion moderates distress from perceived ostracism over time. Journal of Contextual Behavioral Science, 7, 72-80. doi.org/10.1016/j.jcbs.2018.02.001

Vaughan-Johnston, T. I., Quickert, R. E., \& MacDonald, T. K. (2017). Psychological flexibility under fire: Testing the incremental validity of experiential avoidance. Personality and Individual Differences, 105, 335-349. doi:10.1016/j.paid.2016.10.011

Villatte, J. L., Vilardaga, R., Villatte, M., Plumb-Vilardaga, J., Atkins, D. C., \& Hayes, S. C. (2016). Acceptance and Commitment Therapy modules: Differential impact on treatment processes and outcomes. Behavior Research and Therapy, 77, 52-61. Doi: 10.1016/j.brat.2015.12.001

Vowles, K. E., Sowden, G., \& Ashworth, J. (2014). A comprehensive examination of the model underlying acceptance and commitment therapy for chronic pain. Behavior Therapy, 45, 390-401.

Waldeck, D., Tyndall, I., Riva, P., \& Chmiel, N. (2017). How do we cope with ostracism? Psychological flexibility moderates the relationship between everyday ostracism experiences and psychological distress. Journal of Contextual Behavioral Science, 6 , 425-432. Doi:10.1016/j.jcbs.2017.09.001

Wolgast, M. (2014). What does the Acceptance and Action Questionnaire (AAQ-II) really measure? Behavior Therapy, 45, 831-839. doi:10.1016/j.beth.2014.07.002 
Wurpts, I. C., \& Geiser, C. (2014). Is adding more indicators to a latent class analysis beneficial or detrimental? Results of a Monte Carlo study. Frontiers in Psychology, 5, 920. Doi:10.3389/fpsyg.2014.00920

Yu, L., McCracken, L. M., \& Norton, S. (2016). The Self Experiences Questionnaire (SEQ): Preliminary analyses for a measure in people with chronic pain. Journal of Contextual Behavioral Science, 5, 127-133. DOI: 10.1016/j.jcbs.2016.07.006 


\section{Table 1}

The results of the Latent Class Analysis: statistical indices of the solutions were reported.

\begin{tabular}{|c|c|c|c|c|c|c|c|c|}
\hline & nfp & BIC & $2 \Delta L L$ & LMR $p$ & BLRT $p$ & Entropy & n $(\%)$ & $\mathbf{P P}$ \\
\hline K2 (2 classes) & 16 & 21809.5 & 1194.5 & $<.001$ & $<.001$ & .89 & & \\
\hline $\mathrm{C} 1_{\mathrm{K} 2}$ & & & & & & & $286(51.3)$ & .97 \\
\hline $\mathrm{C} 2{ }_{\mathrm{K} 2}$ & & & & & & & $271(48.7)$ & .96 \\
\hline K3 (3 classes) & 22 & 21509.2 & 338.2 & .002 & $<.001$ & .85 & & \\
\hline $\mathrm{C} 1_{\mathrm{K} 3}$ & & & & & & & $153(27.5)$ & .93 \\
\hline $\mathrm{C} 2{ }_{\mathrm{K} 3}$ & & & & & & & $223(40.0)$ & .91 \\
\hline $\mathrm{C} 3_{\mathrm{K} 3}$ & & & & & & & $181(32.5)$ & .95 \\
\hline K4 (4 classes) & 28 & 21392.9 & 154.2 & .066 & $<.001$ & .83 & & \\
\hline $\mathrm{C} 1_{\mathrm{K} 4}$ & & & & & & & $108(19.4)$ & .92 \\
\hline $\mathrm{C} 2{ }_{\mathrm{K} 4}$ & & & & & & & $193(34.7)$ & .90 \\
\hline $\mathrm{C} 3_{\mathrm{K} 4}$ & & & & & & & $173(31.0)$ & .88 \\
\hline $\mathrm{C} 4_{\mathrm{K} 4}$ & & & & & & & 83 (14.9) & .89 \\
\hline K5 (5 classes) & 34 & 21356.3 & 74.4 & .033 & $<.001$ & .83 & & \\
\hline $\mathrm{C} 1_{\mathrm{K} 5}$ & & & & & & & $35(6.3)$ & .86 \\
\hline $\mathrm{C} 2{ }_{\mathrm{K} 5}$ & & & & & & & $124(22.3)$ & .89 \\
\hline $\mathrm{C} 3_{\mathrm{K} 5}$ & & & & & & & $164(29.4)$ & .89 \\
\hline
\end{tabular}


$\mathrm{C}_{\mathrm{K} 5}$ $161(28.9) \quad .88$

C5 55 $73(13.1) \quad .89$

\begin{tabular}{lllllll}
\hline K6 $(6$ classes $)$ & 40 & 21360.5 & 33.7 & .073 & $<.001$ & .80
\end{tabular}

$\mathrm{C} 1_{\mathrm{K} 6}$ $34(6.1) \quad .86$

$\mathrm{C} 2 \mathrm{~K} 6$ $119(21.4) \quad .89$

$\mathrm{C} 3{ }_{\mathrm{K} 6}$ $147(26.4) \quad .87$

$\mathrm{C}_{\mathrm{K} 6}$ $124(22.3) \quad .82$

C5 56 $100(17.9) \quad .84$

C6 6 6

Note. $\mathrm{nfp}=$ number of free parameters; $\mathrm{BIC}=$ bayesian information criterion; $2 \Delta \mathrm{LL}=2$ times $\log$-likelihood difference; LMR $p=p$-value associated to the Lo-Mendell-Rubin adjusted likelihood ratio test; BLRT $p=p$-value associated to the bootstrapped likelihood ratio test; $\mathrm{n}$ $(\%)=$ number and percentage of class members; $\mathrm{PP}=$ posterior probability of a class. 
Table 2

The means and standard deviations across the five measures in the three-class model solution.

\begin{tabular}{cccccc}
\hline & AAQ-II & CFQ & BEAQ & CAS & 5FMQ \\
\hline C1-Low PF & $37.27(1.61)$ & $33.22(1.49)$ & $50.36(1.34)$ & $55.21(0.91)$ & $53.20(0.85)$ \\
C2-Mod PF & $63.48(2.43)$ & $54.06(2.17)$ & $61.01(1.03)$ & $61.85(0.74)$ & $62.77(0.97)$ \\
C3-High PF & $85.60(1.25)$ & $78.79(1.60)$ & $74.61(1.43)$ & $71.14(0.92)$ & $74.18(0.95)$ \\
\hline
\end{tabular}

Note: C1-Low PF refers to Class 1 Low Psychological Flexibility; C2-Mod PF refers to Class 2 Moderate Psychological Flexibility; C3-High PF refers to Class 3 High Psychological Flexibility. AAQ-II = Acceptance and Action Questionnaire-II; CFQ = Cognitive Fusion Questionnaire; BEAQ = Brief Experiential Avoidance Questionnaire; CAS = Committed Action Questionnaire; 5FMQ = 5-Factor Mindfulness Questionnaire. 


\section{Figure Captions}

Figure 1 - The results of the three-class model "K3".

Note. AAQ-II = Acceptance and Action Questionnaire-II; CFQ = Cognitive Fusion

Questionnaire; BEAQ = Brief Experiential Avoidance Questionnaire; CAS $=$ Committed Action Questionnaire; 5FMQ = 5-Factor Mindfulness Questionnaire. High PF = High Psychological Flexibility; Mod PF = Moderate Psychological Flexibility; Low PF = Low Psychological Flexibility

Figure 2 - The results of the ANOVAs conducted on the psychological variables of depression, stress, anxiety (i.e., DASS-21), and positive and negative emotions (I-PANAS); means and standard errors of the K3 classes are displayed. 


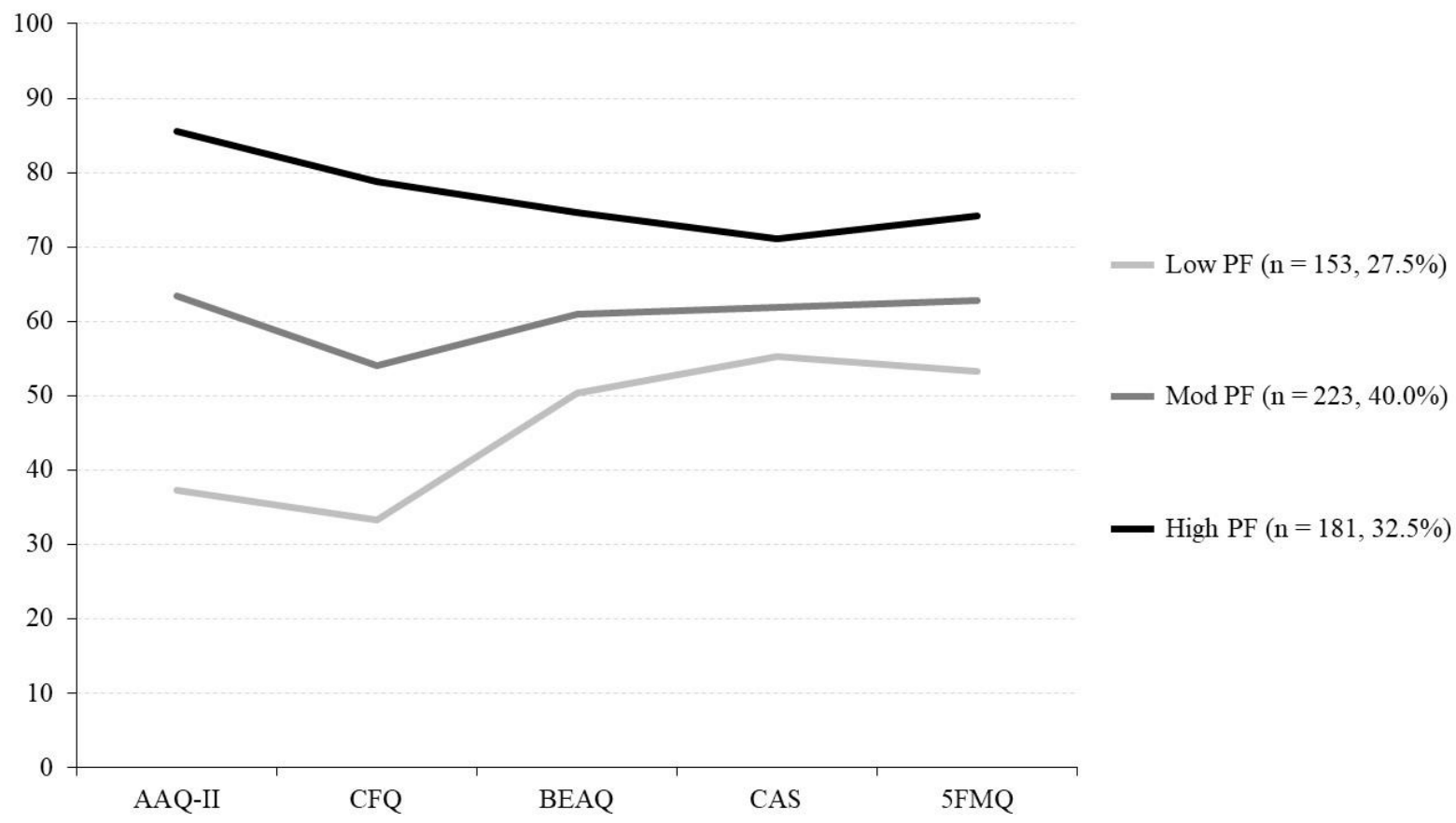

Figure 1 
25

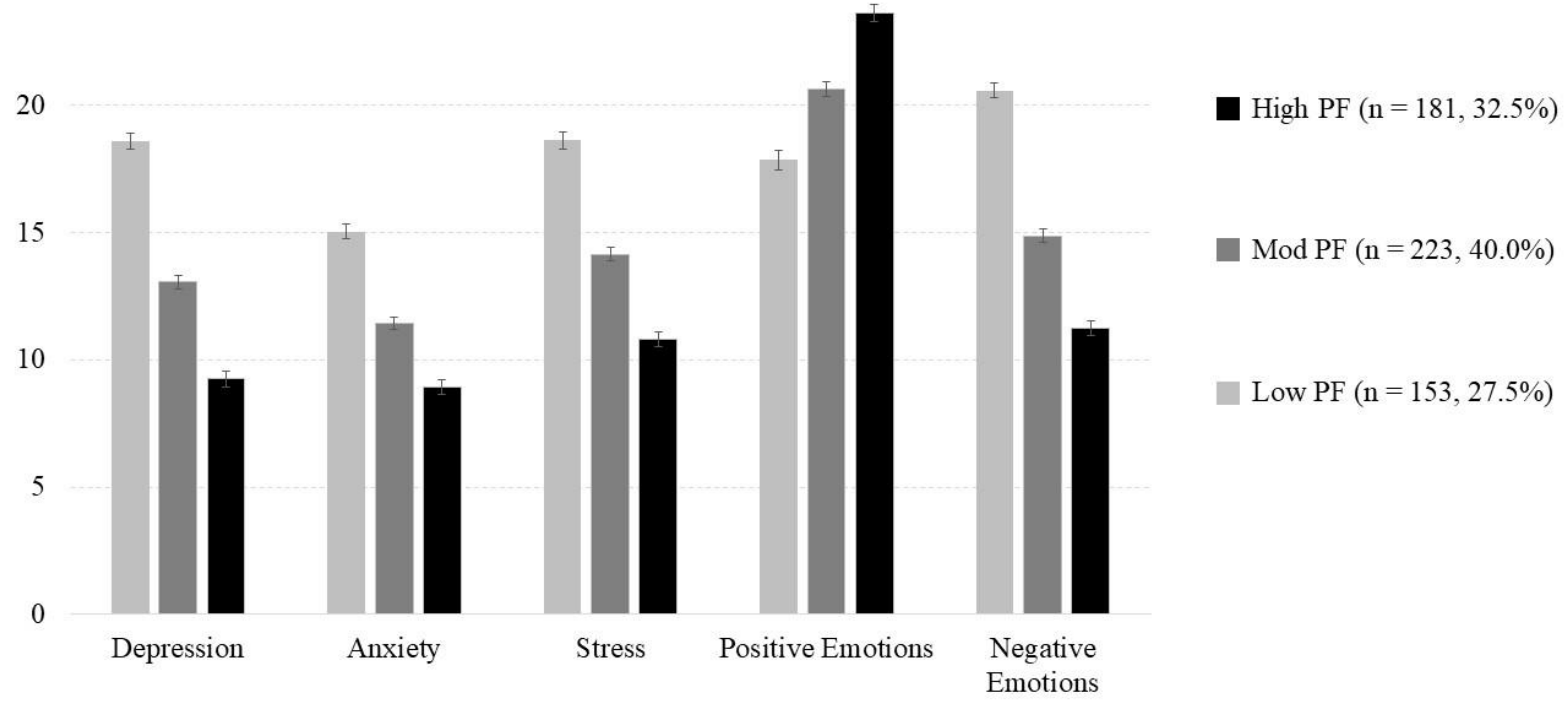

Figure 2 


\section{Appendix}

Contingency tables between sociodemographic variables (in rows) and profiles (in columns) frequencies, percentages within rows and columns, and adjusted standard residuals are reported.

$\begin{array}{lll}\mathrm{C3}_{\mathrm{K} 1} & \mathrm{C3}_{\mathrm{K} 2} & \mathrm{C3}_{\mathrm{K} 3}\end{array}$

\section{Gender}

Males

Frequency

41

85

69

$\%$ within row

21.0

43.6

35.4

$\%$ within column

27.2

39.0

38.3

Adj. Std. Res.

$-2.5$

1.4

1.0

Females

Frequency

110

133

111

$\%$ within row

31.1

37.6

31.4

$\%$ within column

72.8

61.0

61.7

Adj. Std. Res.

2.5

$-1.4$

$-1.0$

\section{Education Level}

$\leq$ High school

Frequency

36

48

34

$\%$ within row

40.7

28.8

$\%$ within column

23.5

21.5

18.8

Adj. Std. Res.

0.8

0.2

$-1.0$

$>$ High school

Frequency

117

175

147 


$\begin{array}{lccc}\text { \% within row } & 26.7 & 39.9 & 33.5 \\ \text { \% within column } & 76.5 & 78.5 & 81.2 \\ \text { Adj. Std. } \text { Res. } & -0.8 & -0.2 & 1.0\end{array}$

\section{Relationship}

\begin{tabular}{|c|c|c|c|c|}
\hline \multirow[t]{4}{*}{ Singles } & Frequency & 75 & 100 & 63 \\
\hline & $\%$ within row & 31.5 & 42.0 & 26.5 \\
\hline & $\%$ within column & 50.7 & 45.7 & 35.2 \\
\hline & Adj. Std. Res. & 2.0 & 0.8 & -2.8 \\
\hline \multirow[t]{4}{*}{ In a relationship } & Frequency & 73 & 119 & 116 \\
\hline & $\%$ within row & 23.7 & 38.6 & 37.7 \\
\hline & $\%$ within column & 49.3 & 54.3 & 64.8 \\
\hline & Adj. Std. Res. & -2.0 & -0.8 & 2.8 \\
\hline
\end{tabular}

